Original Research Article

\title{
Study of drug prescription pattern in diarrhoea patients admitted to paediatric ward in a government tertiary care hospital in Maharashtra, India
}

\author{
Vinod S. Deshmukh ${ }^{1}$, Swapnil P. Chube ${ }^{2 *}$
}

${ }^{1}$ Department of Pharmacology, GMC, Latur, Maharashtra, India ${ }^{2}$ Department of Pharmacology, SRTR GMC, Ambajogai, Maharashtra, India

Received: 08 May 2018 Accepted: 30 May 2018

\section{*Correspondence to: \\ Dr. Swapnil P. Chube, Email: swapnilchube@ gmail.com}

Copyright: (C) the author(s), publisher and licensee Medip Academy. This is an openaccess article distributed under the terms of the Creative Commons Attribution NonCommercial License, which permits unrestricted noncommercial use, distribution, and reproduction in any medium, provided the original work is properly cited.

\begin{abstract}
Background: World Health Organization (WHO) has defined diarrhoea as, 'the passage of loose stools by an individual, at least thrice a day or more frequently than normal'. It is most commonly caused by intestinal infection, mainly viral. Every year there are about 2 billion cases of diarrhoea worldwide, a second leading cause of mortality in children below the age of 5 years. WHO estimated that antibiotic treatment was necessary in only one in twenty cases of childhood diarrhoea. Yet huge resources are currently spent on anti-diarrhoeal drugs annually, most rendered useless or harmful. This study was proposed to evaluate the utilization pattern of drugs prescribed for diarrhoea in children, in a government tertiary care hospital in Maharashtra.

Methods: This cross-sectional observational study was carried out in the paediatric ward of government tertiary care hospital, Maharashtra. All patients of age less than twelve years with diarrhoea admitted to paediatric ward within the study period of January 2015 - June 2016 were included in the study. Patients older than twelve years or admitted with other gastrointestinal diseases or comordbid conditions were excluded. Statistical analysis was done using descriptive statistics.

Results: Majority of the patients admitted were males and more than half the patient population were in the age group of less than or equal to 3 years. Polypharmacy was found to be present in the prescribing pattern, with average, more than 4 drugs prescribed for diarrhoea treatment, in each prescription. Majority drugs were prescribed using brand names and parenteral route. Use of antibiotics was also found to be inappropriate in majority of the cases.

Conclusions: The study highlighted the importance of drug utilisation studies and pointed out inappropriate drug prescribing trends for diarrhoea cases in a tertiary care hospital in Maharashtra.
\end{abstract}

Keywords: Diarrhoea, Drug utilisation study, Defined Daily Dose, Paediatrics, Polypharmacy

\section{INTRODUCTION}

Children constitute $40 \%$ of India's population. ${ }^{1}$ This is a vital period for rapid growth and development. Therefore, drugs should be used very cautiously and rationally for this age group. Acute respiratory infection, acute diarrhoea and viral fever are common childhood illnesses accounting for the major proportion of patients in the paediatric age group. ${ }^{2}$

Amongst these, acute diarrhoeal disease has remained a challenging problem to the medical profession and to the community in third world countries even today. World Health Organisation (WHO) estimates that worldwide, four million children under the age of five, die each year 
from diarrhoea. ${ }^{3}$ This makes diarrhoea the second leading cause of death in children. ${ }^{4}$ In hospitals up to a third of total admissions to paediatrics are due to diarrhoeal diseases and up to $17 \%$ of all deaths in indoor paediatric patients are diarrhoea related. ${ }^{5}$ In India, diarrhoea accounts for $8.2 \%$ of the total disease burden, contributing 22 million Disability Adjusted Life Years (DALYs), the highest among communicable diseases. ${ }^{6}$

Inspite of the self- limiting nature of majority of these illnesses, polypharmacy and inappropriate use of antibiotics and other drugs is resorted to. ${ }^{1}$ It is known that pathogens causing diarrhoea in children below the age of five years are mainly viruses, while both bacterial and viral pathogens are implicated in adults. ${ }^{7}$ WHO estimates that antibiotic treatment is necessary in only one in twenty cases of childhood diarrhoea. Yet huge resources are currently spent on anti-diarrhoeal drugs annually, most of which are useless or harmful. ${ }^{7}$

Appropriate drug utilization studies are important to evaluate proper utilization of drugs, in terms of efficacy, safety, convenience of the patient and economic aspects at all levels in the chain of drug use. ${ }^{6}$ Drug utilization research can increase our understanding of drug utilisation patterns, like the extent of use of a particular drug at a certain moment and/or in a certain area for example in a country, region, community or hospital.

Till date, a large number of drug utilisation studies have been carried out in adults but very few such studies are documented in the paediatric age group. ${ }^{8}$ Also, diarrhoea is a major cause of mortality among the paediatric age group. ${ }^{3-5}$ Thus, considering the paucity of data, important for both the society and the medical professionals, this study was carried out to evaluate the drug prescribing pattern for diarrhoea in children admitted in a government tertiary care hospital in Maharashtra.

\section{METHODS}

This cross-sectional observational study was carried out in the paediatric ward of government tertiary care hospital, Maharashtra, India. All patients of age less than twelve years with diarrhoea admitted to paediatric ward within the study period of January 2015 - June 2016 were included in the study. Patients older than twelve years admitted with gastrointestinal diseases like dysentery, cholera, giardiasis, etc. or with co-morbid conditions (HIV, Immunosuppressed, pneumonia, urinary tract infections, etc.) were excluded from the study. Patients who Left Against Medical Advice (LAMA) or those who absconded were also excluded from the study. Patient's prescription sheet was evaluated to collect data which was recorded in the Case Record Form, which included patient profile, that is, patient's initials, gender, age, immunisation status. Also recorded were the chief complaints, their onset, duration and frequency, any other comorbid conditions, fever or any other health complaint. Analysis was done by using tables, charts and other descriptive statistics. The drug utilization pattern was analysed using WHO drug prescribing indicators and was compared with the standard treatment guidelines issued by the World Health Organisation (WHO) and Indian Academy of Paediatrics (IAP). Drug utilization indicators like Defined Daily Dose (DDD) and Anatomic Therapeutic Chemical (ATC) classification were used to analyse drug utilization pattern.

Defined Daily Dose (DDD) was calculated using formulae:

$\mathrm{DDD} / 100 \mathrm{BED}$ days $=\underline{\text { Total dose }(\mathrm{mg}) \text { during study periodx } 100}$ DDD OF drug $x$ Study duration (days) $x$ BED

Strength $\mathrm{X}$ average BED occupancy rate:

Average Bed Occupancy Rates $=$ Total IPD for a given period Available beds $x$ No. of days in that period

\section{RESULTS}

The total number of patients admitted for acute diarrhoea in the paediatric ward of this study site was 1000 . Out of these, a total of $587(58.7 \%)$ were male patients and 413 $(41.3 \%)$ patients admitted were females. All these patients were 12 years old or younger.

It was observed that more than half the patient population admitted with acute diarrhoea in the paediatric ward, was in the age group of $\leq 3$ years. This age group contributed $59.9 \%$ of the diarrhoea affected patient population. Those within the age range of 8-12 years were minimum affected by diarrhoea with only $16.5 \%$ patients being admitted in this age range (Table 1 ).

It was also observed that, out of the total admissions to the hospital's paediatric ward for diarrhoea, male patients were affected more than females in all the age groups, except those in the 4-7-year age group, as shown in Table 1.

Table 1: Age and gender-wise distribution of the study population $(\mathrm{n}=\mathbf{1 0 0 0})$.

\begin{tabular}{|lllll|}
\hline $\begin{array}{l}\text { Age } \\
\text { group }\end{array}$ & $\begin{array}{l}\text { No. of } \\
\text { males }\end{array}$ & $\begin{array}{l}\text { No. of } \\
\text { females }\end{array}$ & Total & Percentage \\
\hline 0-3 years & 356 & 243 & 599 & $59.9 \%$ \\
\hline 4-7 years & 115 & 121 & 236 & $23.6 \%$ \\
\hline 8-12 years & 116 & 49 & 165 & $16.5 \%$ \\
\hline Total & 587 & 413 & 1000 & $100 \%$ \\
\hline
\end{tabular}

\section{WHO drugs prescribing indicators}

\section{No. of drug encounters per prescription}

During the study period, a total of 1000 patients were admitted for diarrhoea in the paediatric ward in the hospital and it was found that, on an average, each patient prescription had more than 4 drugs prescribed for treatment of diarrhoea at the hospital. 
Table 2: Average number of drugs encountered per prescription.

\begin{tabular}{|c|c|c|}
\hline $\begin{array}{l}\text { Total } \\
\text { number of } \\
\text { drugs } \\
\text { prescribed } \\
\text { (A) }\end{array}$ & $\begin{array}{l}\text { Total number of } \\
\text { encounters } \\
\text { (1 encounter = } 1 \\
\text { patient) } \\
\text { (B) }\end{array}$ & $\begin{array}{l}\text { Average } \\
\text { number of } \\
\text { drugs per } \\
\text { encounter } \\
\text { (A/B) }\end{array}$ \\
\hline 4612 & 1000 & 4.6 \\
\hline
\end{tabular}

Percentage of drugs prescribed by generic name / brand name

As shown in Table 3, 2276 (49.35\%) drugs were prescribed using generic names and 2336 (50.65\%) drugs were prescribed using brand names. As shown in Figure 1, out of the total drugs prescribed, 2245 (48.68\%) drugs were given by oral route and $2367(51.32 \%)$ were given by parenteral route.

Table 3: Number of drugs prescribed by generic name / brand name.

\begin{tabular}{|llll|}
\hline Route & $\begin{array}{l}\text { Drugs } \\
\text { prescribed by } \\
\text { generic name }\end{array}$ & $\begin{array}{l}\text { Drugs } \\
\text { prescribed by } \\
\text { brand name }\end{array}$ & Total \\
\hline Oral & 1335 & 910 & 2245 \\
\hline Parenteral & 941 & 1426 & 2367 \\
\hline Total & 2276 & 2336 & 4612 \\
\hline
\end{tabular}

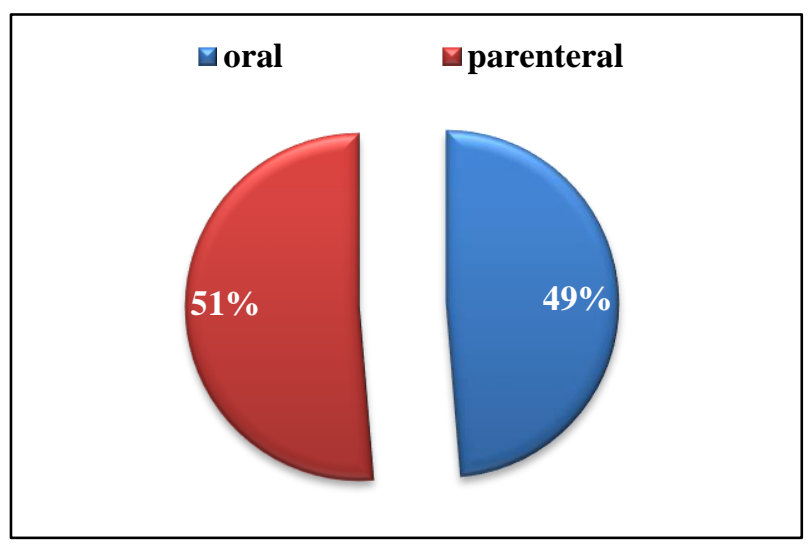

Figure 1: Routes of drug prescriptions.

Out of the total 1000 prescriptions studied, a majority of prescriptions were carrying brand names exclusively. These contributed to $547(54.7 \%)$ prescriptions in all. The ones having generic names exclusively were just 266 (26.6\%). 187 (18.7\%) prescriptions, referred to, as 'mixed', in the above figure, featured both generic names and brand names in the same prescription sheet.

Percentage of antibiotics prescribed and their appropriateness

In this study, the total number of patients (encounters) that were prescribed antibiotics for acute diarrhoea was 413
(41.3\%), out of the total 1000 patients admitted. As shown in Table 4, amongst the antibiotics prescribed, a majority, that is, $909(94.98 \%)$ antibiotics were given by parenteral route versus just $48(5 \%)$ prescribed by oral route. Also, 957 antibiotics were found to be prescribed in 413 prescriptions. This implies 2.32 antibiotics were prescribed on an average per prescription.

Table 4: Number and routes of antibiotics prescribed.

\begin{tabular}{|llll|}
\hline $\begin{array}{l}\text { Total no. of } \\
\text { prescriptions } \\
\text { with } \\
\text { antibiotics }\end{array}$ & $\begin{array}{l}\text { Oral } \\
\text { antibiotics }\end{array}$ & $\begin{array}{l}\text { Parenteral } \\
\text { antibiotics }\end{array}$ & $\begin{array}{l}\text { Total no. } \\
\text { of } \\
\text { antibiotics } \\
\text { prescribed }\end{array}$ \\
\hline 413 & 48 & 909 & 957 \\
\hline
\end{tabular}

Appropriateness of antibiotics prescribed in hospitalized patients was analysed using the modified Kunin's criteria. As stated in the Table 5, Categories I, II and IIa indicate appropriate therapy. Categories III, IV, and V indicate that there was some inappropriate choice of, or improper use of anti-microbial agent by the physicians managing the problem.

Table 5: Modified Kunin's criteria for appropriatness of antibiotics prescribed for Diarrhoea. ${ }^{9}$

\begin{tabular}{|c|c|}
\hline $\begin{array}{l}\text { Kunin's } \\
\text { criteria } \\
\text { category }\end{array}$ & Justification \\
\hline I & $\begin{array}{l}\text { Agree with the use of anti-microbial } \\
\text { therapy/prophylaxis. The treatment is } \\
\text { appropriate in terms of choice of drug, } \\
\text { dose, dosage regimen, duration of therapy. }\end{array}$ \\
\hline II & $\begin{array}{l}\text { Agree with use of anti-microbial } \\
\text { therapy/prophylaxis, but a potentially fatal } \\
\text { bacterial infection cannot be ruled out or } \\
\text { prophylaxis is probably appropriate } \\
\text { although advantage derived remain } \\
\text { controversial. Microbiology testing was } \\
\text { performed, but report was inconclusive. } \\
\text { However the protocol was appropriate. }\end{array}$ \\
\hline II a & $\begin{array}{l}\text { Agree with the use of one anti-microbial } \\
\text { agent but the use of other(s) is unjustified. }\end{array}$ \\
\hline III & $\begin{array}{l}\text { Agree with the use of anti-microbial } \\
\text { therapy/prophylaxis, but a different } \\
\text { antimicrobial is preferred (usually less } \\
\text { expensive or less toxic). }\end{array}$ \\
\hline IV & $\begin{array}{l}\text { Agree with the use of anti-microbial } \\
\text { therapy/prophylaxis, but a modified dose } \\
\text { and or /proper duration is recommended. }\end{array}$ \\
\hline $\mathrm{V}$ & $\begin{array}{l}\text { Disagree with the use of anti-microbial } \\
\text { therapy/prophylaxis, administration is } \\
\text { unjustified - Infections viral in origin, } \\
\text { Antimicrobials not required }\end{array}$ \\
\hline
\end{tabular}

It was observed that in majority of the prescriptions, that is, in $299(72.4 \%)$ prescriptions; use of antibiotics was uncalled for (category V). The second highest number of 
prescriptions with antibiotics was observed to be, in Category II of the Kunin's criteria and 46 (11.14\%) such prescriptions were observed. Minimum number of prescriptions, $4(0.96 \%)$ each, were observed to be in categories I and III of the modified Kunin's criteria (Figure 2).

Cefotaxime was the most common and azithromycin was the least commonly prescribed antibiotic. Cefotaxime was prescribed in 287 prescriptions, ceftriaxone in 73 prescriptions, Amoxicillin in 50, Metronidazole in 35, O2 (Ofloxacin + Ornidazole) in 25, Septran (Sulfamethoxazole + Trimethoprim) in 12, Doxycycline in 9, Albendazole in 7, Azithromycin in 6 and Amikacin in 5 prescriptions (Figure 3).

The total number of ORS sachets prescribed in this study was 784. Zinc preparations prescribed was a meagre 490 preparations out of the total 4612 drugs prescribed in the study.

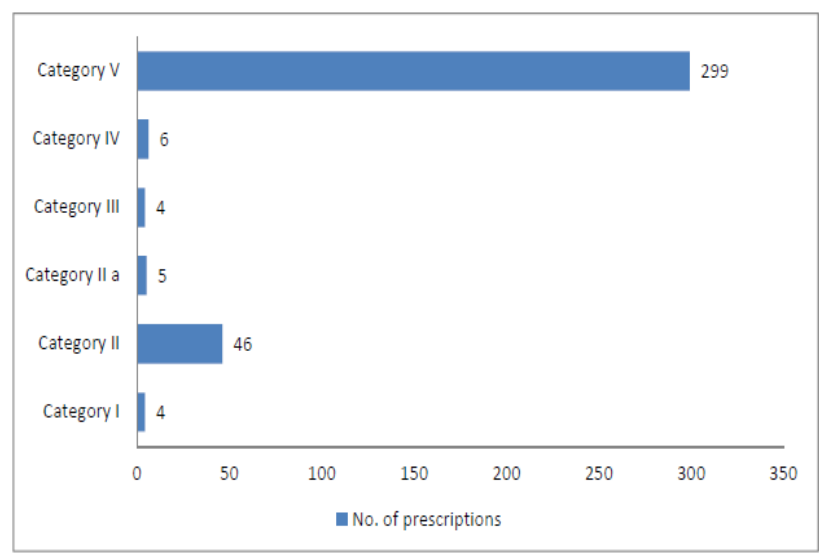

Figure 2: Appropriateness of antibiotic prescription using Kunin's criteria.

Table 6: Drug prescription analysis using ATC/DDD system.

\begin{tabular}{|llllll|}
\hline Name of drug & Route of administration & ATC code & DDD $(\mathrm{gm})$ & PDD $(\mathrm{gm})$ & PDD/DDD \\
\hline Amoxicillin & Oral & J01CA04 & 1 & 0.99 & 0.99 \\
\hline Doxycycline & Oral & J01AA02 & 0.1 & 0.099 & 0.99 \\
\hline Azithromycin & Oral & J01FA10 & 0.3 & 0.297 & 0.99 \\
\hline Ofloxacin+Ornidazole & Oral & J01RA09 & 1.4 & 1.389 & 0.99 \\
\hline Sulfamethoxazole+Trimethoprim & Oral & J01EE01 & 2.4 & 2.38 & 0.99 \\
\hline Albendazole & Oral & P02CA03 & 0.4 & 0.39 & 0.97 \\
\hline Paracetamol & Oral, parenteral & N02BE01 & 3 & 2.97 & 0.99 \\
\hline Digoxin & Oral & C01AA05 & 0.25 & 0.24 & 0.96 \\
\hline Domperidone & Oral & A03FA03 & 30 & 29.77 & 0.99 \\
\hline Ondansetron & Oral, parenteral & A04AA01 & 16 & 15.88 & 0.99 \\
\hline Cetirizine & Oral & R06AE07 & 10 & 9.92 & 0.99 \\
\hline Propranolol & Oral & C07AA05 & 0.16 & 0.15 & 0.93 \\
\hline Clobazam & Oral & N05BA09 & 20 & 19.85 & 0.99 \\
\hline Lansoprazole & Oral & A02BC03 & 30 & 29.77 & 0.99 \\
\hline Pantoprazole & Parenteral & A02BC02 & 40 & 39.70 & 0.99 \\
\hline Ranitidine & Parenteral & A02BA02 & 0.3 & 0.29 & 0.96 \\
\hline Amikacin & Parenteral & J01GB06 & 1 & 0.99 & 0.99 \\
\hline Amoxicillin+Clavulanic acid & Parenteral & J01CR02 & 3 & 2.97 & 0.99 \\
\hline Metronidazole & Parenteral & J01XD01 & 1.5 & 1.48 & 0.98 \\
\hline Ceftriaxone & Parenteral & J01DD04 & 2 & 1.98 & 0.99 \\
\hline Cefotaxime & Parenteral & J01DD01 & 4 & 3.97 & 0.99 \\
\hline Vancomycin & Parenteral & J01XA01 & 2 & 1.98 & 0.99 \\
\hline Calcium gluconate & Parenteral & A12AA03 & 3 & 2.98 & 0.99 \\
\hline Vitamin A & Parenteral & A11CA01 & 50 & 49.63 & 0.99 \\
\hline Vitamin D & Parenteral & A11CC04 & 1 & 0.99 & 0.99 \\
\hline Vitamin K & Parenteral & B02BA02 & 2 & 1.98 & 0.99 \\
\hline Dexamethasone & Parenteral & H02AB02 & 1.5 & 1.48 & 0.98 \\
\hline Hydrocortisone & Parenteral & H02AB09 & 30 & 29.77 & 0.99 \\
\hline $\begin{array}{l}\text { Saccharomyces boulardii } \\
\text { (ECONORM) }\end{array}$ & Oral & A07FA02 & 1 & 0.99 & 0.99 \\
\hline $\begin{array}{l}\text { Lactic acid producing organism } \\
\text { (prowel) }\end{array}$ & Oral & A07FA51 & 1 & 0.99 & 0.99 \\
\hline
\end{tabular}




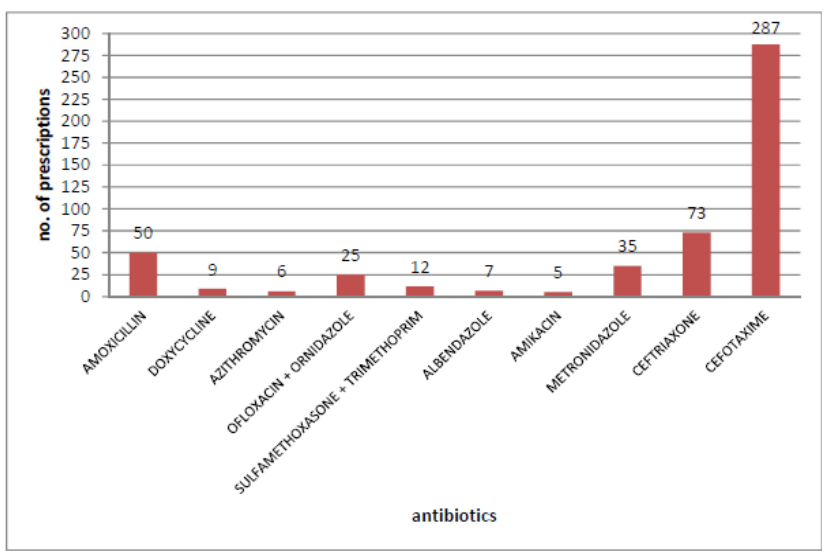

Figure 3: Prescription pattern of antibiotics.

\section{Drug use pattern as per ATC/DDD system}

As shown in Table 6, the ATC code and DDD for the particular drug was found using the WHO reference DDDs and ATC codes' website. ${ }^{10}$

The ratio of Prescribed Daily Dose to Defined Daily Dose was calculated. Most of the drugs had PDD to DDD ratio of 0.99 , with none of the ratios being equal to 1 or more than 1 .

\section{DISCUSSION}

It was observed in this study that, more than half the patient population admitted with acute diarrhoea in the paediatric ward, was in the age group of $\leq 3$ years. This age group contributed $59.9 \%$ of the diarrhoea affected patient population in this study. This is in accordance to a study done by Panchal JR et al. in which the mean age of the patients was $2.77 \pm 2.84$ years and most patients $(45 \%)$ were less than 1year of age. ${ }^{8}$ A study conducted by Sharma $\mathrm{L}$ et al, also echoed this finding. They reported that $45 \%$ admissions were in the age group of less than 3 years. ${ }^{11}$

A few possible explanations to this observation are that most children are weaned from breast feeding at an age of 6 months. The possibility of infection by feco-oral route is more likely during this period because of improper and unhygienic feeding practices. Another explanation is that, maternal antibodies are declining at this age and the child is yet to develop its own defenses against infections. ${ }^{7}$ This makes the children in the age group of less than 3 years to be more vulnerable to acute diarrhoeal infections.

It was also observed in this study that, out of the total admissions for diarrhoea to the hospital's paediatric ward, male patients were affected more than females in all the age groups, except those in the 4-7 year age group. The predominance of diarrhoea in female children in the age group of 4-7 years in this study cannot be explained. However, the predominance of male admissions is assumed to be because, the male children are more likely to be brought to the hospital for treatment than the females, sighting the Indian - society's traditional gender bias. A study conducted by Pandey A et al. has also reported a similar finding that, the male patients are taken to a health care professional or a hospital more frequently than the female patients. ${ }^{12}$ Similar finding was reported by another study conducted by Reddy S et al, where 57\% (57) patients admitted were males as against $43 \%$ (43) female patients. ${ }^{13}$

\section{Drug prescribing pattern in study population}

In this study, it was found that, on an average, each patient prescription had more than 4 drugs prescribed for diarrhoea treatment at the hospital. A study conducted by Panchal JR et al. reported even higher degree of drug usage with an average of $7.53 \pm 1.87$ drugs prescribed per patient. ${ }^{7}$ A study conducted by Shankar PR et al. also reported that, the average number of drugs per paediatric inpatient was $4.5 \pm 3.7 .{ }^{11}$ A study conducted in children under 5 years of age suffering from acute diarrhoea in Bangladesh by Alam MB et al. reported, the average number of drugs prescribed per patient to be 1.5 - which is much lower than that found in this study. ${ }^{14}$

The average number of drugs per prescription per encounter is an important index in prescribing practices. With the recommended limit of 2 drugs per encounter and the international average of 2.2 drugs per prescription, this study reported a higher degree of drugs prescribed per patient prescription. ${ }^{15}$ Hence, it is evident that the practice of poly - pharmacy is prevalent in this setup which may suggest irrational prescribing practices. The reasons for this practice could range from lack of accuracy / confidence in the diagnosis or lack of awareness of the standard treatment guidelines. Administration of intravenous fluids may be one of the reasons causing increase in the average number of drugs per prescription.

This study reported that, a majority of the drugs ( $>50 \%)$ were prescribed by their brand names. Similar findings were reported by a study done in Kathmandu by Palikhe $\mathrm{N}$, where $59 \%$ of the total drugs prescribed were by brand names. ${ }^{16}$ Some studies however, reported appropriate prescription practices. A study done by Vishwanath $\mathrm{M}$ et al. reported $62.3 \%$ prescriptions by generic name. ${ }^{1}$ Another study done by Shankar PR et al. reported $58.1 \%$ of the total prescriptions to be by generic name. ${ }^{11}$ Substitution of generic drugs results in decreasing the overall cost of therapy and is therefore recommended. ${ }^{17}$

Out of the total 1000 prescriptions in this study, 88.3\% prescriptions had atleast one injectable prescribed in them. Studies by Vishwanath et al. and Shankar PR et al, reported $49.06 \%$ and $48.9 \%$ encounters respectively, with an injection prescribed, which is much less compared to this study. ${ }^{1,18}$ Intravenous fluids prescribed (Ringer's Lactate and Dextrose) were also included in injectables, which is the probable reason for a high number of injectables in this study. 
In this study, $51.32 \%$ (2367) drugs were given by parenteral route and $48.68 \%$ (2245) drugs were given orally. Mezgebe HB et al, reported in their study that, the most common route of drug administration $-71.8 \%$, was parenteral route while only $24.1 \%$ was oral route. ${ }^{19}$ Similar findings were reported by Bordoloi et al, with only 102 $(32.7 \%)$ prescriptions having oral formulations and 210 $(67.3 \%)$ given injections. ${ }^{20}$ Parenteral route of drug administration increases the length of the hospital stay which in turn exposes the children to nosocomial and multidrug resistant infections. The parenteral route may be necessary in some of the paediatric patients but is more expensive.

Out of the total 1000 patients included in this study, 413 $(41.3 \%)$ patients were prescribed atleast 1 antibiotic in their prescription. A similar finding was presented in a study by Bordoloi et al, who reported 39 (40.6\%) encounters with atleast 1 antibiotic prescribed. ${ }^{20}$ On the other hand, in a study conducted by Panchal JR et al, $25.5 \%$ encounters with antibiotics were reported, which is much lower than this study. ${ }^{8}$

Also, the average number of antibiotics prescribed per prescription was 2.32 in this study. A study conducted by Ashraf $\mathrm{H}$ et al. reported a higher antibiotic prescribing trend, with 2.37 antibiotics prescribed per prescription. ${ }^{21} \mathrm{~A}$ slightly lower number of 1.97 was reported by Panchal et al. in their study. ${ }^{7}$ Bordoloi et al, reported even lesser antibiotic usage with on an average only 1 antibiotic prescribed per prescription. ${ }^{20}$ Most episodes of acute diarrhoea are caused by virus, and not bacteria. Thus, the use of antimicrobials without a rational basis constitutes an inappropriate use which should be discouraged. Such use not only adds to the cost of treatment, but also increases the risk of adverse reactions, and the development of resistant bacteria. A reason for the slightly higher prescribing trend in this setup may be attributed to the fact that, it is not possible to distinguish clinically, the episodes of diarrhoea caused by enterotoxigenic $E$. coli from those caused by agents resistant or not responsive to antimicrobials, such as rotavirus. Hence, antibiotics are prescribed more like an empirical therapy for patients having acute diarrhoea. $3^{\text {rd }}$ generation Cephalosporins (Cefotaxime) was the most commonly prescribed antibiotic in this study. Panchal et al, and Maniar $\mathrm{M}$ et al, reported similar observations in their studies. ${ }^{7,22}$ However, in a study conducted by Sharma L et al, Norfloxacin was the most common antimicrobial agent used alone or in combination with either Metronidazole or Tinidazole. ${ }^{11}$ The reason for use of antibiotics in acute diarrhoea may be in anticipation of a quicker recovery from diarrhoea, which is obviously not justified and shows a lack of awareness about the standard treatment guidelines for treatment of diarrhoea.

In this study, amongst the prescriptions with antibiotics, it was observed that a majority of them, that is $299(72.4 \%)$ prescriptions were classified as category $\mathrm{V}$ of the modified Kunin's Criteria while only $4(0.96 \%)$ prescriptions were classified as category I. That is, above $50 \%$ of the prescriptions with antibiotics were classified as inappropriate for treatment of acute diarrhoea in this study. This is because majority of the diarrhoea causing infections are viral in origin, where use of antimicrobials for therapy/prophylaxis, is not justified as is stated in the WHO guidelines for treatment of acute diarrhoea in children. A similar result was reported by Panchal et al. who stated that, the use of antimicrobials was not necessary in $63(61.17 \%$ ) patients (category V) in their study. ${ }^{7}$ Inappropriate use of antimicrobials in children with diarrhoea has been reported by other researchers as well. A study by Howteerakul $\mathrm{N}$ and others in Thailand reported $72.6 \%$ of prescriptions containing antibiotics to be in category $\mathrm{V}$ of the modified Kunin's criteria. ${ }^{23}$ The large percentage of category $\mathrm{V}$ prescriptions in this study may be due to factors like, doubtful diagnosis and underuse of laboratory investigations, resulting in an empirical use of antimicrobials.

The number of ORS sachets prescribed in this study was 784. This was $17 \%$ of the total drugs prescribed in the study. A much lower number of just $13 \%$ of the total drugs prescribed, was reported in a study conducted by Panchal et al. ${ }^{7}$ On the other hand, in a study conducted by Pathak et al, a much higher, $58 \%$ contribution of ORS to the total drugs prescribed, was noted. ${ }^{24}$ A slightly higher usage than this study was reported by Singh $\mathrm{J}$ et al. They recorded $22 \%$ of the total drugs prescribed for acute diarrhoea to be ORS in their study. ${ }^{25}$

Around $11 \%$ of the drugs prescribed in this study were contributed by zinc preparations. This accounted for a mere 490 drugs out of the total 4612 drugs prescribed in this study. A much higher number was prescribed in a study conducted by Pathak et al, who reported zinc preparations to be $22 \%$ of the total drugs prescribed in their study. ${ }^{24}$ ORS and Zinc preparations are recommended in treatment of diarrhoea because it reduces the severity and frequency of diarrhoea and thus helps in a quicker recovery. However, there still seems to be a slight indifference towards the standard treatment guidelines of both WHO and IAP by the treating clinicians which is reflected by the lower prescribing trends of both these drugs in this hospital.

\section{Drug use pattern as per ATC and DDD systems}

All the drugs (except intravenous fluids) prescribed were classified according to the Anatomical Therapeutic Chemical (ATC) and Daily Defined Dose (DDD) classification. The ATC classification system divides drugs into different groups according to the organ or system on which they act, their chemical, pharmacological and therapeutic properties. ${ }^{26}$ The 'DDD' concept was developed to overcome objections raised against the traditional units of the measurement of drug consumption and to ensure comparability between the various drug utilization studies which were carried out at different locations and at different time periods. ${ }^{27}$ It is important to 
remember that the DDD is the assumed average maintenance dose per day for a drug which is used for its main indication in adults.

The prescribed daily dose (PDD) is defined as the average dose prescribed according to a representative sample of prescriptions. When the difference between PDD and DDD is substantial, it is important to take this difference into consideration when evaluating and comparing drug utilization figures. ${ }^{27}$

In this study, most of the drugs had PDD to DDD ratio of 0.99 , with none of the ratios being equal to 1 or more than 1.

When the PDD/DDD ratio is either less than or greater than 1, it may indicate that there is either under or over utilization of drugs, respectively. Having said that, it is important to note that, the PDD can vary according to both the illness treated and national therapeutic practices. The PDDs also vary substantially between different countries, for example, PDDs are often lower in Asian than in Caucasian populations. This may be attributable to the physiological variations in drug metabolisms of individuals belonging to different races. Because of this it may seem as if, there is underutilization of a particular drug as per the PDD/DDD ratio in the studies carried out in Asians. This may be the probable explanation for all the PDD/DDD ratios to be less than 1 in this study too. Also, the DDDs obtained from the WHO ATC/DDD website are based on international data and are applicable for management of conditions of moderate intensity. Hence, WHO encourages countries to have their own DDD list based on indigenous data. ${ }^{26,27}$

There are certain limitations in this study. The study was conducted in only one setup, thus multi-centric analysis in a given geographic location could not be found out. Hence, the results of this particular study cannot be extrapolated to the general population. Also, since the patient population is entirely Asian, the ATC/DDD data which is suggested by WHO according to the world population tends to show a substantial difference.

\section{CONCLUSION}

From this study we recommend that, practitioners should abide by the standard treatment guidelines, given by the WHO and IAP, in this case, which would definitely reduce the practice of polypharmacy and unnecessary or at times inappropriate antibiotic prescribing practices. Polypharmacy not only increases the cost to the patient, but also puts the patient at a higher risk of Adverse Drug Reactions (ADRs) which cause discomfort to the patient and may also prove to be life threatening. Unwanted, inappropriate prescribing of antibiotics causes more harm than benefit. Apart from raising hospitalisation costs and predisposing the patient to adverse side effects, such practices cause development of more and more resistance to commonly used antibiotics in practice.

\section{ACKNOWLEDGEMENTS}

Authors would like to thank the Department of Paediatrics for their co-operation during this study.

Funding: No funding sources

Conflict of interest: None declared

Ethical approval: The study was approved by the Institutional Ethics Committee

\section{REFERENCES}

1. Vishwanath M, Reddy SN, Devadas S. Assessment of drug utilization in hospitalized children at a tertiary care teaching hospital. J Chem Pharm Res. 2014;6(2):592-8.

2. Shamshy K, Begum I, Perumal P. Drug utilization of antimicrobial drug in paediatrics population in a tertiary care hospital in erode, Tamilnadu, India. Int $\mathbf{J}$ Pharm Tech Res. 2011;3(3):1530-6.

3. World Health Organization. The treatment of diarrhoea: A manual for physicians and other senior health workers. 4th rev. Geneva: Department of Child and Adolescent Health and Development, World Health Organization; 2005.

4. WHO. Diarrhoeal disease [Internet]. World Health Organization. 2016 [cited 13 July 2016]. Available at: http://www.who.int/mediacentre/factsheets/fs330/en/i ndex.html.

5. Pebley, Anne R. The State of the World's Children 1989. Popul Dev Rev. 1989;15(2):376.

6. Kumar AM, Thulasi RK, Ramasamy C. Cross sectional prospective study on drug utilization in an outpatient paediatric department of tertiary care teaching hospital. Glob J Pharmacol. 2013;7(2):99102.

7. Panchal JR, Desai CK, Iyer GS, Patel PP, Dikshit RK. Prescribing pattern and appropriateness of drug treatment of diarrhoea in hospitalised children at a tertiary care hospital in India. Int J Med Public Health. 2013;3:335-41.

8. Suman RK, Mohanty NC, Mohanty IR, Deshmukh YA. The study of drug usage patterns in pediatric Patients at MGM hospital, Navi Mumbai. World J of Pharmace Resear. 2014;3(4):734-43.

9. Deshmukh VS, Khadke VV, Patil AW, Lohar PS. Study of prescribing pattern of antimicrobial agents in indoor patients of a tertiary care hospital. Int $\mathbf{J}$ Basic Clin Pharmacol. 2013;2:281-5.

10. ATC/DDD Index 2016 [Internet]. WHO Collaborating Centre for Drug Statistics Methodology Norwegian Institute of Public Health; 2016 [cited 2016 September 5]. Available at: http://www.whocc.no/atc_ddd_index/

11. Sharma L, Gupta R, Kapadia R, Gupta K, Singhal S, Gupta JK, Mathur M, Sharma K. Auditing of prescriptions in relation to diarrhea in children below 5 years of age: a multicenter study. Int Jof Basic \& Clin Pharmacol. 2017 Jan 16;4(6):1208-13. 
12. Pandey A, Sengupta PG, Mondal S, Gupta D, Manna B, Ghosh S, et al. Gender differences in healthcareseeking during common illnesses in a rural community of West Bengal, India. J Health Popul Nutr. 2002;20:306-11.

13. Reddy S. Prescribing pattern of drugs in paediatric wards at a tertiary care teaching hospital. IJPRR. 2015;5(4):374-8.

14. Alam MB, Ahmed FU, Rahman ME. Misuse of drugs in acute diarrhoea in under five children. Bangladesh Med Res Counc Bull. 1998;24:27-31.

15. Mummad J. Audit of paediatric prescriptions for the common paediatric problems. Pak J Med Sci. 2007;23:932-5.

16. Palikhe N. prescribing pattern of antibiotics in paediatric Hospital of Kathmandu valley. Journal of Nepal Health Research Council. 2004;2(2):31-6.

17. Quick JD, Hogerzeil HV, Velasquez G, Rago L. Twenty-five years of essential medicines. Bull World Health Organ. 2002;80(11):913-4.

18. Shankar PR, Upadhyay DK, Subish P, Dubey A, Mishra P. Prescription patterns among paediatric inpatients in a teaching hospital in Western Nepal. Singapore Med J. 2006;47:261-4.

19. Mezgebe HB, Tadesse B, Legesse B. Antibiotics prescribing pattern in paediatric unit of Ayder referral hospital, Tigray region, Northern Ethiopia. J of Sci and Innov Resea. 2015;4(2):57-60.

20. Bordoloi P. Drug utilization study in the management of acute diarrhoea in the Paediatrics department at a tertiary health care institution. British $\mathbf{J}$ of Med and Heal Resea. 2016;3(7):46-55.

21. Ashraf H, Handa S, Khan NA. Prescribing pattern of drugs in out-patient department of Child Care Centre in Moradabad city. IJPSRR. 2010;3(2):1-5.
22. Maniar M, Shah I, Rao S. Antibiotic prescription patterns in children for upper respiratory tract infections and diarrhoea. JK Science. 2013;15(2):7781.

23. Howteerakul N, Higginbotham N, Dibley MJ. Antimicrobial use in children under five years with diarrhoea in a Central Region Province, Thailand. Southeast Asian J Trop Med Public Health. 2004;35:181-7.

24. Pathak D, Pathak A, Marrone G, Diwan V, Lundborg CS. Adherence to treatment guidelines for acute diarrhoea in children up to 12 years in Ujjain, India-a cross-sectional prescription analysis. BMC infectious diseases. 2011 Dec;11(1):32.

25. Singh J, Bora D, Sachdeva V, Sharma RS, Verghese T. Prescribing pattern by doctors for acute diarrhoea in children in Delhi, India. J Diarrhoeal Dis Res. 1995;13(4):229-31.

26. WHO. WHO Collaborating Centre for Drug Statistics Methodology: Guidelines for ATC classification and DDD assignment 2015. Oslo: WHO; 2015.

27. WHO International Working Group for Drug Statistics Methodology. Introduction to Drug Utilization Research [Internet]. Oslo, Norway: WHO Collaborating Centre for Drug Utilization Research and Clinical Pharmacology; 2003 [cited 2016 July 20]. Available

at: http://apps.who.int/medicinedocs/pdf/s4876e/s4876e. pdf.

Cite this article as: Deshmukh VS, Chube SP. Study of drug prescription pattern in diarrhoea patients admitted to paediatric ward in a government tertiary care hospital in Maharashtra, India. Int J Basic Clin Pharmacol 2018;7:1403-10. 